\title{
PARTICIPAÇÃO DA SOCIEDADE EM ÁREAS PROTEGIDAS: PERSPECTIVAS DA LEGISLAÇÃO AMBIENTAL BRASILEIRA
}

\author{
Renata Souza ${ }^{1}$ \\ Universidade Federal do Rio de Janeiro (UFRJ) \\ Giuliana Franco Leal ${ }^{2}$ \\ Universidade Federal do Rio de Janeiro (UFRJ) \\ Fabianne Manhães Maciel $^{3}$ \\ Universidade Federal Fluminense (UFF)
}

\section{RESUMO}

O debate relacionado à participação em áreas protegidas abarca questões benéficas tanto para a própria política de proteção da natureza quanto para a população, pois as práticas participativas podem ser de grande valia para o Estado - visto que este deixa de ser o único responsável pelas políticas sociais - e para a sociedade civil - pois a ampliação da participação em instâncias políticas e decisórias é de relevância para garantir autonomia, empoderamento e diminuição das injustiças, além de gerar benefícios sociais e econômicos. Portanto, o presente trabalho analisa a legislação brasileira relacionada às áreas protegidas, no intuito de compreender como o princípio da participação é inserido nesses documentos, a partir da execução da técnica de análise documental. Ao realizar a pesquisa observou-se que a temática da participação está presente na legislação sobre áreas protegidas desde a aprovação da Lei n. 4.771/65, porém sem que houvesse uma radicalidade nas formas de participação, sendo esta limitada ao auxílio que a sociedade poderia prover ao Estado. Após a promulgação da Constituição de 1988, observa-se nas leis que a sucedem

1 Doutoranda no Programa de Pós-graduação em Ciências Ambientais e Conservação da UFRJ. Mestre em Psicossociologia de Comunidades e Ecologia Social pelo Programa de Pós-graduação EICOS da UFRJ. Graduada em Ciências Biológicas (Licenciatura e Bacharel) pela UFF. Especialista em Geologia do Quaternário pelo Museu Nacional da UFRJ. E-mail: resouza@ufrj.br

2 Doutora e mestre em Sociologia pela Universidade Estadual de Campinas (UNICAMP), com estágio de doutorado na École de Hautes Etudes en Sciences Sociales (EHESS). Graduada em Ciências Sociais pela UNICAMP. Professora na UFRJ (graduação, pós-graduação stricto sensu e pós-graduação lato sensu). ORCID: https://orcid.org/0000-0002-0233-339X / e-mail: giulianafrancoleal@yahoo.com.br

3 Doutora em Direito pela Universidade do Estado do Rio de Janeiro (UERJ). Mestre em Direito pelo Centro Universitário Fluminense (UNIFLU). Professora Adjunta e Coordenadora do Curso de Direito na UFF. E-mail: fabiannemanhaes@id.uff.br 
um maior aprofundamento no entendimento do conceito de participação, remetendo a possibilidades de compartilhamento de decisões e gestão entre Estado e sociedade civil.

Palavras-chave: inclusão social; legislação ambiental; Unidades de Conservação.

\section{PARTICIPATION OF SOCIETY IN PROTECTED AREAS: OUTLOOK FROM BRAZILIAN ENVIRONMENTAL LEGISLATION}

\section{ABSTRACT}

The related debate to participation in protected areas includes issues which are beneficial to nature protection policy and to the population, since participatory practices can be of great value to the State-because it ceases to be the only responsible for social policies - and for civil society-since, the expansion of political participation is relevant to guarantee autonomy, empowerment, reduction of injustices, and generate social and economic benefits. Therefore, the present work analyzes the Brazilian law related to protected areas, in order to understand how the principle of participation is inserted in these documents, from the execution of the documentary analysis technique. It was observed that the participation theme is present in the legislation on protected areas since the Lei $n .4 .771 / 65$, but without there being radicality in the participation forms, which is limited to the aid that society could provide to the State. After the promulgation of the Constituição de 1988, it is observed in the laws a deeper understanding of the concept of participation, which refers to possibilities for decision-making and management between the State and civil society.

Keywords: environmental laws; protected areas; social inclusion. 


\section{INTRODUÇÃO}

O estudo científico da temática da participação não é recente, este remota ao século XVIII, a partir das ideias de Jean-Jacques Rousseau (PATEMAN, 1992). A ênfase na participação em Rousseau é observada principalmente no livro 'Do Contrato Social', e se dá através da concepção de um modelo alternativo de sociedade, determinado pela existência de dois pressupostos: o primeiro marcado pela defesa da igualdade material, através da distribuição equitativa das propriedades privadas e o segundo pelo estabelecimento de uma 'vontade geral', identificada pelos sujeitos coletivos que exprimem um interesse comum (que contrasta com sua ideia de 'vontade de todos', definida como o somatório das vontades privadas dos indivíduos) (COUTINHO, 2011). Nesse sentido, a sociedade ideal de Rousseau se estrutura a partir de "um interesse comum capaz de se sobrepor aos vários interesses individuais conflitantes" (COUTINHO, 2011, p. 36).

Pateman (1992) interpreta que a centralidade da concepção da participação em Rousseau reside na função educativa atribuída pelo autor a este conceito e em sua acepção de liberdade. No que tange a atribuição educativa, a participação e a educação se retroalimentam, já que o indivíduo só desenvolve as capacidades necessárias a um processo participativo, participando. Ademais, é dentro de um processo participativo que o indivíduo aprende a se desapegar de seus interesses privados em prol dos interesses coletivos.

Contudo, mais antiga que as próprias ideais de Rousseau a respeito desse tema, é a aplicação prática da participação como estratégia de política pública. Nas sociedades grega e romana, a participação na vida política constituía-se em um direito inalienável dos cidadãos, muito embora a concepção de cidadania nessas sociedades fosse extremamente restrita a alguns grupos - mulheres, escravos e estrangeiros eram excluídos (COMPARATO, 1989).

De modo distinto, na atualidade, o sufrágio se tornou universal, mas as diferenças tanto de ordem econômica, quanto de ordem política, influenciam na participação direta da sociedade nas políticas públicas; por conseguinte, a parte da população menos abastada é constantemente excluída das decisões políticas. Ademais, pesa ainda na exclusão atual das políticas públicas, outras formas de desigualdades, como as desigualdades de gênero, de raça e de sexualidade (MIGUEL, 2016).

Devido a essa conjuntura política que o conceito de participação vem 
sendo amplamente desenvolvido e debatido por diversos pesquisadores, agências internacionais e segmentos sociais, sendo, portanto, evocado tanto por atores que buscam na prática da participação o aprofundamento da democracia e o compartilhamento de decisão e poder, quanto por grupos que intencionam tutelar e dominar outros segmentos sociais. Estes últimos se aproveitam da legitimidade e prestígio desse conceito para exercer controle sobre outros segmentos sociais (DEMO, 1988; LOUREIRO, 2012).

Portanto, a discussão a respeito da participação é complexa e agrega inúmeras formas de entendimento dessa prática, desde manifestações bemintencionadas de legitimar e instaurar equidade de decisão política, social e econômica, até a emergência de projetos participativos impostos de "cima para baixo", com o intuito de apenas minimizar os conflitos e de manter a posição privilegiada de determinados grupos.

Muitos são os autores que definem das mais diversas formas o conceito de participação. Para o delineamento do presente trabalho, realizou-se um compêndio das definições formuladas por Bordenave (1985), Demo (1988) e Loureiro (2004; 2012). Nesse sentido, participação é vista como um processo coletivo, no qual instituições de diversos tipos e indivíduos representantes de diferentes segmentos devem negociar de maneira que todos tenham voz, direito de opinião e de decisão. O processo participativo deve incitar a corresponsabilidade entre o Poder Público e a sociedade civil e fortalecer a democracia. A participação prima pelo acesso igualitário nas instâncias decisivas, empoderamento das populações locais, acesso aos bens socialmente produzidos e superação das injustiças.

\section{PARTICIPAÇÃO NO BRASIL}

No Brasil a ideia de participação surge de maneira mais organizada na década de 1960. Nessa época a participação não era entendida como princípio para o enraizamento da democracia. O que se convencionou denominar de participação popular tinha como foco a melhoria da condição de vida das camadas populares; não havia preocupação de envolver a população nas decisões do Estado (LAVALLE, 2011).

Na subsequente década de 1970, não houve muitos avanços com relação à temática da participação e esta se manteve vinculada ao auxílio às classes mais desfavorecidas. A participação não foi, até então, tratada como 
forma de democratizar o Estado e as decisões eram desempenhadas pelo Poder Público, sem envolvimento da população. A forma de se entender a temática da participação nesse período está claramente ligada ao governo ditatorial da época, que comprometeu os direitos políticos dos cidadãos (DAGNINO; OLVERA; PANFICHI, 2006; GOHN, 2011; LAVALLE, 2011).

De acordo com Gohn (2011), na década de 1970, participar era um conceito praticado de forma mecanicista. Estruturas de participação eram criadas para garantir a presença de indivíduos, no entanto, nessas instituições a população não tinha a oportunidade de participar efetivamente, a participação centralizava-se no nível da escuta. De acordo com a autora, "participar era ter gente lá” (GOHN, 2011, p. 54).

Um aprofundamento no entendimento do conceito de participação ocorre apenas vinte anos mais tarde, na década de 1980. De 1980 em diante, o conceito passa a remeter à participação da sociedade civil nas decisões e formulações políticas públicas (LAVALLE, 2011). O marco decisivo na ampliação do entendimento da participação como aprofundamento do processo democrático e de envolvimento da população nos processos decisórios ocorre a partir da promulgação da Constituição de 1988 (DAGNINO, 2002).

A Lei Maior do país apresenta no seu primeiro artigo o princípio da soberania popular "todo o poder emana do povo, que o exerce por meio de representantes eleitos ou diretamente" (BRASIL, 1988, art. $1^{\circ}$ ). Complementarmente, ao princípio da soberania popular, o exercício da participação é garantido através de alguns mecanismos como: iniciativa popular em processos legislativos, referendos e plebiscitos (BRASIL, 1988, art. 14, incisos I, II, III; art. 27, § 4; art. 29, inciso XIII; art. 49, inciso $\mathrm{XV}$; art. $61, \S 2^{\circ}$ ). É ainda compulsório que nos planejamentos municipais sejam empregadas estratégias de cooperação de associações representativas da sociedade civil (BRASIL, 1988, art. 29, inciso XII).

Os mecanismos para o exercício da participação presente na Constituição Federal impulsionaram, nos anos 1990, a criação de uma série de instituições participativas (como conselhos, orçamento participativos, fóruns e conferências) em áreas como saúde, educação, assistência social e meio ambiente (AVRITZER, 2016).

No entanto, o final dos anos 1980 e o início dos anos 1990 foram marcados pela emergência de políticas neoliberais que vislumbravam a criação de instituições participativas com o objetivo de transferir para a 
sociedade os deveres que seriam de responsabilidade do próprio Estado. Segundo Dagnino (2004), isso se reflete numa confluência perversa, devido à existência de dois projetos que são diferentes em suas finalidades, mas utilizam o mesmo argumento para alcançá-las, que constitui na promoção de uma sociedade ativa e participativa. $O$ projeto democrático participativo é marcado pelo desejo da ampliação democrática e envolvimento da sociedade, enquanto o neoliberal visa à diminuição das responsabilidades sociais do Estado. Essa comunhão dos argumentos dos diferentes discursos proporciona uma dimensão contraditória para as experiências genuinamente participativas do projeto democrático participativo, e é exatamente nesse ponto que reside a perversidade denunciada por Dagnino (2004).

Nesse sentido, no Brasil, desde que a discussão a respeito da participação se ampliou nos anos 1960, a temática vem ganhando adeptos e diferentes formas de participação vêm crescendo no país. De acordo com Avritzer (2011), as políticas participativas são cada vez mais definidas como estratégicas na gestão pública, e esse aumento do envolvimento social na gestão do que o autor denomina de "coisa pública" é perceptível na proliferação da instituição de conselhos gestores no século XXI.

No entanto, na contramão dessa tendência de aprofundamento democrático por via de instituições participativas, no ano de 2019 foi publicado o Decreto n. 9.759, de 11 de abril de 2019, que extingue e estabelece diretrizes, regras e limitações para colegiados da administração pública federal. Apelidado de "revogaço", esse documento extingue e estabelece limitações para todos os órgãos colegiados federais criados por decretos, atos normativos inferiores aos decretos, atos de outro colegiado e até mesmo aqueles cuja lei não versa sobre as competências ou a composição dos colegiados (BRASIL, 2019, art. $1^{\circ}$ ). Consideram-se inclusos na definição de colegiados: os conselhos, as comissões, os grupos, as juntas, as equipes, as mesas, os fóruns, as salas e "qualquer outra denominação dada ao colegiado" (BRASIL, 2019, art. $2^{\circ}$ ). Desse modo, o Decreto n. 9.759/19 inclui uma infinidade de instituições passíveis de serem extintas ou limitadas, ademais, revoga o Decreto n. 8.243, de 23 de maio de 2014, que institui a Política Nacional de Participação Social - PNPS e o Sistema Nacional de Participação Social - SNPS (BRASIL, 2019, art. 10).

4 No dia 12 de junho de 2019, o Supremo Tribunal Federal (STF) analisou uma Ação Direta de Inconstitucionalidade (ADI), ajuizada pelo Partido dos Trabalhadores, que solicita a suspensão de dispositivos do Decreto n. 9.759/19. Porém, o julgamento foi suspenso e até a data de envio do presente artigo ainda não havia sido retomado. 
O debate a respeito da participação da sociedade em áreas protegidas é respaldado no âmbito do Direito Ambiental, composto por uma série de princípios que norteiam a criação, aplicação e interpretação das normas jurídicas. Um dos princípios fundamentais do Direito Ambiental constitui justamente no princípio da participação. De acordo com Milaré (1998, p. 4) o princípio da participação "expressa à ideia de que para a resolução dos problemas do ambiente deve ser dada especial ênfase à cooperação entre o Estado e a sociedade, através da participação dos diferentes grupos sociais na formulação e na execução da política ambiental".

No Brasil, a participação na esfera ambiental é observada no caput do art. 225 da Constituição Federal: "todos têm direito ao meio ambiente ecologicamente equilibrado, bem de uso comum do povo e essencial à sadia qualidade de vida, impondo-se ao Poder Público e à coletividade o dever de defendê-lo e preservá-lo para as presentes e futuras gerações" (BRASIL, 1988).

Isto posto, nas questões que tangem ao meio ambiente, a participação constitui-se em um direito-dever, que possui como premissa a participação da sociedade de maneira ativa tanto no debate de questões ambientais, quanto na formulação, nas decisões, na execução e na fiscalização das políticas ambientais (MALTEZ, 2016).

Para o devido exercício da participação podem ser utilizados alguns mecanismos previstos em lei. Entre estes, se encontram a iniciativa popular em processos legislativos, visando à criação de normas ambientais (BRASIL, 1988, art. 18, § $2^{\circ}$ ), os instrumentos judiciais, caracterizados pela ação civil pública (BRASIL, 1985), o mandado de segurança, o mandado de injunção e a ação popular (BRASIL, 1988, art. 5², inciso LXXIII).

Há ainda a possibilidade de participação por meio de plebiscitos (BRASIL, 1988, art. 14, inciso I), conferências e fóruns criados pelo Poder Público ou por iniciativa popular, através da representação da sociedade civil organizada em órgãos colegiados responsáveis pela formulação de diretrizes e acompanhamento de políticas públicas (como conselhos e Comitês de Bacia Hidrográfica) e na realização de audiências públicas, onde são ouvidos os interesses e preocupações da população (BRASIL, 1986, art. 11, § 2 ${ }^{\text {o }}$ BRASIL, 1999, art. 32).

Segundo Maltez (2016), classifica-se a participação em quatro esferas distintas: administrativa (audiência pública, consulta pública, órgãos colegiados, direito de petição e direito à informação), legislativa (plebiscito, referendo e iniciativa popular de projeto de lei), judicial (mandado de 
segurança, ação popular e ação civil pública) e outras esferas (como associações, blogs, internet, ONGs e outras entidades civis ambientais).

$\mathrm{Na}$ esfera administrativa, é relevante ressaltar o direito à informação. É imperativo que para haver participação de maneira efetiva sem que ocorra manipulação de um grupo por outro, o acesso à informação deve ser universalizado e de qualidade (MILARÉ, 1998; MACHADO, 2013). Nesse contexto, destaca-se a Lei $n .^{\circ}$ 10.650/2002, que dispõe sobre o acesso público aos dados e informações existentes nos órgãos e entidades integrantes do Sistema Nacional do Meio Ambiente (Sisnama).

Portanto, o princípio da participação no escopo do Direito Ambiental assegura a participação ativa da sociedade nas políticas ambientais. $\mathrm{O}$ debate a respeito da participação da sociedade em áreas protegidas deve ser reconhecido na legislação brasileira referente à proteção da natureza. As principais leis que instituem e regulamentam as áreas protegidas dentro do Estado brasileiro - a Lei n. 9.985 de 18 de julho de 2000, que institui o Sistema Nacional de Unidades de Conservação (SNUC), o Decreto n. 5.758 de 13 de abril de 2006, que institui o Plano Estratégico Nacional de Áreas Protegidas (PNAP), e em menor grau o Código Florestal - abordam em diferentes graus a temática da participação.

De acordo com Irving, Giuliani \& Loureiro (2008), a participação da sociedade em áreas protegidas é de vital importância para efetivar a política de proteção da natureza, pois possibilita tornar as medidas de proteção das áreas protegidas mais eficientes.

A discussão relativa à participação é de grande relevância devido à complexidade dos problemas ambientais, que requer decisões flexíveis, inovadoras, interdisciplinares e transparentes. Desse modo, é necessário que essas decisões agreguem uma diversidade de conhecimentos e valores (REED, 2008).

Entretanto, a participação em áreas protegidas não tem relevância apenas para auxiliar nas estratégias políticas de conservação dessas áreas. De acordo com autores que estudaram a temática da participação, a exemplo de Bordenave (1985), Demo (1988) e Loureiro (2004; 2012), uma maior influência da sociedade nas instituições participativas pode gerar o empoderamento da população local, proporcionar autonomia para os moradores, auxiliar na superação de injustiças, suscitar o fortalecimento da cultura local e gerar benefícios sociais e econômicos.

Após esta breve introdução, pode-se perceber a importância da inserção de práticas participativas para a conservação de áreas protegidas e para a 
população que vive dentro e nos entornos dessas áreas. Por essa razão, com o presente trabalho objetivou-se averiguar como é inserido o princípio da participação na legislação brasileira referente às áreas protegidas, de modo a investigar como cada lei aborda a temática da participação, analisar quais são as práticas participativas resguardadas por cada uma das leis e relacionar com o contexto histórico/político no qual essas leis foram sancionadas.

\section{METODOLOGIA}

Como o intuito do presente trabalho consiste em buscar compreender como o princípio da participação é enunciado na legislação relativa às áreas protegidas, optou-se por realizar o processo de análise documental.

A análise documental é definida por Godoy (1995) como sendo a pesquisa em materiais que não obtiveram um tratamento prévio, ou mesmo quando já houve um tratamento, mas se torna interessante definir um novo olhar para os dados.

Nesse sentido, foram averiguadas as principais leis brasileiras relacionadas às áreas protegidas, que são: a Lei n. 4.771, de 15 de dezembro de 1965; a Lei n. 7.803, de 18 de julho de 1989; a Lei n. 12.651, de 25 de maio de 2012; a Lei n. 9.985, de 18 de julho de 2000 e o Decreto n. 5.758, de 13 de abril de 2006. Ademais, foram realizadas pesquisas na Constituição da República Federativa do Brasil, de 1988, em particular no Capítulo VI, intitulado "Do Meio Ambiente".

O trabalho de realizar uma análise documental, entretanto, não descarta a necessidade da realização de uma pesquisa bibliográfica prévia, pois, de acordo com Minayo (2002), esta é indispensável para o andamento do trabalho de pesquisa, já que para a autora (op. cit.), é necessário articular a fundamentação teórica com o objeto a ser pesquisado, de forma a criar uma base teórica para se olhar os dados.

Portanto, a primeira etapa dessa pesquisa constituiu na realização deuma pesquisa bibliográfica em livros, artigos, periódicos, teses e dissertações. Esta foi efetuada na intenção de realizar um maior aprofundamento sobre a temática pesquisada, e assim articular os conceitos teóricos com as observações oriundas da análise documental. 


\section{RESULTADOS E DISCUSSÃO}

A temática da participação em áreas protegidas segue a tendência dos debates sobre participação no Estado brasileiro. É possível perceber a gradual expansão dos discursos referentes ao envolvimento da sociedade na gestão de áreas protegidas nos instrumentos legais que foram instituídos no Brasil, principalmente a partir dos anos 1960.

Ao analisar o Código Florestal de 1965 (Lei n. 4.771/65, revogada pela Lei n. 12.651/12), é possível observar a temática da participação em alguns artigos, como no art. 16, que versa sobre a instituição de florestas de domínio privado, pois é conferida ao proprietário da terra a responsabilidade de proteger os recursos florestais existentes em sua propriedade. Entretanto, o Estado não se exime do encargo de conservar essas áreas, como é possível notar no art. 18: "nas terras de domínio privado, onde seja necessário o florestamento e o reflorestamento, o Poder Público poderá fazê-lo sem desapropriá-las, se não o fizer o proprietário". Desse modo, o Código Florestal de 1965 confia à população o compromisso de proteger os recursos naturais e a biodiversidade em consonância com o Estado, antecipando o direito-dever da participação na esfera ambiental estabelecido na Constituição de 1988.

Ademais, é possível observar, ao analisar o Código Florestal de 1965, que existe certa preocupação com as particularidades das populações residentes onde as florestas são instituídas. No artigo 27, o qual discorre sobre a proibição do uso de fogo nas florestas e demais formas de vegetação, o parágrafo único expressamente dispõe que: "se as peculiaridades locais ou regionais justificarem o emprego do fogo em práticas agropastoris ou florestais, a permissão será estabelecida por ato do Poder Público". Nos artigos 42 e 43 pode-se notar a preocupação com a conscientização da população, já que estes discorrem sobre a inclusão de textos sobre educação florestal nos livros escolares, sobre a adição obrigatória de programas e dispositivos de interesse florestal nas estações de rádio e televisão e sobre a obrigatoriedade de se instituir a semana florestal nas escolas e em estabelecimentos públicos.

Art. 42. Dois anos depois da promulgação desta Lei, nenhuma autoridade poderá permitir a adoção de livros escolares de leitura que não contenham textos de educação florestal, previamente aprovados pelo Conselho Federal de Educação, ouvido o órgão florestal competente.

$\S 1^{\circ}$ As estações de rádio e televisão incluirão, obrigatoriamente, em suas 
programações, textos e dispositivos de interesse florestal, aprovados pelo órgão competente no limite mínimo de cinco (5) minutos semanais, distribuídos ou não em diferentes dias.

$\S 2^{\circ}$ Nos mapas e cartas oficiais serão obrigatoriamente assinalados os Parques e Florestas Públicas.

$\S 3^{\circ}$ A União e os Estados promoverão a criação e o desenvolvimento de escolas para o ensino florestal, em seus diferentes níveis.

Art. 43. Fica instituída a Semana Florestal, em datas fixadas para as diversas regiões do País, do Decreto Federal. Será a mesma comemorada, obrigatoriamente, nas escolas e estabelecimentos públicos ou subvencionados, através de programas objetivos em que se ressalte o valor das florestas, face aos seus produtos e utilidades, bem como sobre a forma correta de conduzi-las e perpetuá-las (BRASIL, 1965, art. 42; art. 43).

Nesse sentido, observa-se a abordagem sobre o princípio da informação, que apesar de não haver maior aprofundamento nos termos da participação da sociedade como agente decisório, é importante, pois permite a maior divulgação dos assuntos relacionados aos temas tratados na Lei n. 4.771/65, e, dessa forma, uma maior apropriação, por parte da população, desses conhecimentos. Este fato pode viabilizar a articulação de alguns atores e a mobilização. Ademais, o acesso à informação garante o entendimento das linguagens técnicas, muitas vezes desconhecidas pela população no geral.

Portanto, a análise do Código Florestal de 1965 revela a existência de atenção com o caráter partilhado sobre as responsabilidades de proteção da natureza. No entanto, é importante ressaltar que esta proteção, apesar de compartilhada, possui cunho autoritário, pois é realizada de maneira compulsória. $\mathrm{O}$ indivíduo divide a obrigação da conservação, mas não é conferida à sociedade a capacidade de decidir. A participação está estabelecida no nível de auxílio ao Estado e no nível da conscientização da população. Assim, enquadra-se no entendimento de participação disseminado nas décadas de 1960 e 1970, pelo qual o diálogo não é contemplado e as decisões não são partilhadas com a sociedade.

Essa maneira autoritária de lidar com a questão da participação faz parte do contexto histórico da época. A partir de um golpe de Estado, inaugurou-se em 1964 uma ditadura militar que perdurou por vinte anos. Nesse período, a política foi assinalada por intervenções do Estado nas instâncias participativas. Carvalho (2009) relata que havia intervenções nos sindicatos, os direitos de lideranças sindicais, intelectuais e políticas foram cassados, vários órgãos representativos de trabalhadores e estudantes 
foram fechados, a existência de partidos políticos foi limitada pelo Governo, o Congresso foi desfeito e as eleições diretas para presidente foram eliminadas. Dentro dessa conjuntura a ideia de participação não envolve o aprofundamento democrático, pelo contrário, se insere para controlar e silenciar a população.

O que Dagnino, Olvera e Panfichi (2006) denominam de projeto autoritário, marcado no Brasil e em outros países da América Latina pela ascensão da ditadura militar, é caracterizado por uma verticalização nas relações entre Estado e sociedade - de forma que a sociedade seja coibida de influenciar as políticas públicas - e uma política clientelista. Ademais, práticas ligadas à repressão aos indivíduos que subvertam a regulamentação estabelecida são constantemente adotadas nesse projeto.

Apesar de o projeto autoritário cercear os direitos políticos dos cidadãos e limitar a participação da sociedade na forma da escuta e no auxílio às classes menos abastadas, no Brasil, foi a luta e a resistência contra o Regime Militar que impulsionou a geração de novos atores sociais, que pretendiam o retorno da democracia, de modo que a participação da sociedade na gestão pública torna-se central para o projeto político que se opunha ao projeto autoritário (JACOBI, 1999; DAGNINO, 2002).

$\mathrm{O}$ auge da mobilização popular se deu na campanha pelas eleições diretas, em 1984. Havia na época um sentimento generalizado de euforia popular por ter participado da construção disto (CARVALHO, 2009). Nesse clima, a recém-eleita Assembleia Constituinte redigiu e aprovou aquela que ficou conhecida como Constituição Cidadã, por ser a mais democrática que já houve no Brasil, na qual os direitos políticos alcançaram a maior amplitude que já tiveram na história brasileira. Essa Constituição é marcada pelo restabelecimento de práticas democráticas, por abordar a questão da participação, pois concede aos cidadãos o direito de participar da política para além do exercício do voto, e ainda versa sobre o estabelecimento de instituições participativas (DAGNINO, 2002; LAVALLE, 2011; AVRITZER, 2011).

Após, é publicada a Lei $\mathrm{n}^{\circ} 7.803 / 89$, que altera a redação da Lei n. 4.771/65. Entre outras determinações, a Lei n. 7.803/89 apresenta a categoria de Reserva Legal. A Reserva Legal é definida como sendo uma "área localizada no interior de uma propriedade ou posse rural, excetuada a de preservação permanente, necessária ao uso sustentável dos recursos naturais, à conservação e reabilitação dos processos ecológicos, à conservação da biodiversidade e ao abrigo e proteção de fauna e flora 
nativas" (BRASIL, 1965, art. $1^{\circ}, \S 2^{\circ}$, inciso III). Nesse sentido, são os proprietários que realizam a manutenção da Reserva Legal, o que caracteriza o compartilhamento da responsabilidade de proteção entre o Poder Público e a sociedade.

Assim, é possível observar que a inclusão da sociedade já é cogitada nesse documento, desde a sua criação em 1965, incluindo as posteriores alterações realizadas em 1989, porém a noção de inclusão social é ainda realizada de maneira sutil. Na Lei n. 7.803/89, não é possível notar a preocupação em instaurar equidade de decisão política, a sociedade não é cogitada como ativamente participante do processo de gestão e de formulação de políticas públicas.

O princípio da participação, no sentido de inserir a sociedade em um processo coletivo de negociação e decisão, além da corresponsabilidade entre sociedade e Poder Público, é evidenciado de forma mais clara em 2000, a partir da promulgação do Sistema Nacional de Unidades de Conservação (SNUC - Lei n. 9.985/00). A ênfase concedida à participação da sociedade nas estratégias de gestão e a necessidade de se considerar as demandas sociais, culturais e econômicas locais são visualizadas em algumas das diretrizes que regem o SNUC, estipuladas no art. $5^{\circ}$, como é o caso das diretrizes II, III, V, VIII e IX:

II - assegurar os mecanismos e procedimentos necessários ao envolvimento da sociedade no estabelecimento e na revisão da política nacional de unidades de conservação;

III - assegurar a participação efetiva das populações locais na criação, implantação e gestão das unidades de conservação;

$\mathrm{V}$ - incentivar as populações locais e as organizações privadas a estabelecerem e administrarem unidades de conservação dentro do sistema nacional;

VIII - assegurar que o processo de criação e a gestão das unidades de conservação sejam feitos de forma integrada com as políticas de administração das terras e águas circundantes, considerando as condições e necessidades sociais e econômicas locais; IX - considerar as condições e necessidades das populações locais no desenvolvimento e adaptação de métodos e técnicas de uso sustentável dos recursos naturais (BRASIL, 2000 , art. $\left.5^{\circ}\right)$.

Além das diretrizes que guiam o Sistema Nacional de Unidades de Conservação (SNUC), outros artigos dessa mesma Lei abordam a questão da participação. $\mathrm{O}$ art. 29 desse documento prevê a obrigatoriedade do estabelecimento de conselhos formados pela organização da sociedade civil nas Unidades de Conservação (UC). 
No entanto, cabe aqui uma ressalva: observa-se que apenas duas categorias de UCs são geridas por conselhos deliberativos, a Reserva Extrativista e a Reserva de Desenvolvimento Sustentável. O restante das Unidades de Conservação regidas pelo SNUC deve, de acordo com esse documento, instituir conselhos consultivos. Fato que para Loureiro, Azaziel e Franca (2003, p. 28) "reflete muito mais uma visão tecnocrática e de baixa tradição participativa dos órgãos do meio ambiente do que um cuidado justificável”. Para os autores (op. cit.), mesmo em se tratando de Unidades de Proteção Integral, o conselho pode tomar decisões dentro dos limites estipulados por cada categoria, não necessariamente conferindo risco à área protegida.

Desse modo, a participação na grande maioria dos conselhos de Unidades de Conservação não radicaliza no nível do compartilhamento de decisões e poder. E, portanto, a análise do desenho institucional desses conselhos retrata, de antemão, um ponto desfavorável para a atividade deliberativa.

Seis anos após a criação do SNUC, foi publicado o Decreto n. 5.758/06, que institui o Plano Estratégico Nacional de Áreas Protegidas (PNAP), este documento reafirma e enfatiza o compromisso das áreas protegidas com a inclusão social e a participação. É possível observar no Decreto n. 5.758/06 o aprofundamento da discussão sobre diversos temas relacionados diretamente com a questão da inclusão social. Este é o primeiro documento analisado onde há referência à conservação da diversidade cultural, logo, subentende-se que a conservação não está restrita à diversidade biológica.

O planejamento para o estabelecimento de novas unidades de conservação, bem como para a sua gestão especifica e colaborativa com as demais áreas protegidas, deve considerar as interfaces da diversidade biológica com a diversidade sociocultural, os aspectos econômicos [...] (BRASIL, 2006, VIII diretriz).

A temática da participação nesse documento é, em comparação com os outros, discutida em grau superior. No princípio XX do seu Anexo, o Decreto n. 5.758/06 versa sobre a "promoção da participação, da inclusão social e do exercício da cidadania na gestão de áreas protegidas, buscando permanentemente o desenvolvimento social, especialmente para as populações do interior e do entorno das áreas protegidas" e afirma ter como diretriz o fortalecimento dos "instrumentos existentes de participação e controle social". De acordo com Irving (2010), os princípios delineados neste documento: 
Trazem à tona e ilustram, neste texto oficial de políticas públicas, uma nova forma de se pensar a proteção da natureza, na qual elementos éticos, culturais e relativos ao compromisso de inclusão social ganham relevância e são expressos como norteadores de movimentos futuros (IRVING, 2010, p. 139).

Nesse sentido, o estabelecimento de instituições participativas é de caráter compulsório nos dois últimos documentos avaliados, pois tanto a Lei n. 9.985/00 quanto o Decreto n. 5.758/06 incluem em seus objetivos, princípios e diretrizes, a discussão sobre a promoção da participação na gestão de áreas protegidas.

A inserção de formas mais abrangentes e ativas de participação na Lei n. 9.985/00 e no Decreto n. 5.758/06 é fruto de um processo histórico de ampliação do entendimento do conceito de participação iniciado nos anos 1980, o qual foi se expandindo gradualmente nos anos subsequentes. A respeito das causas que motivaram a inserção da retórica da participação de maneira mais abrangente, Irving (2010, p. 127) esclarece que: "neste campo de debate e reflexão, a própria noção de conservação da natureza passa a ser também entendida como construção humana, na qual novas lógicas são delineadas, em um esforço de resgate e reintegração entre sociedade e natureza".

No entanto, na contramão dessa tendência de reforçar o conceito da participação como compartilhamento de responsabilidades, decisões e troca de informações, a Lei n. 12.651/12, que dispõe sobre a proteção da vegetação nativa, substituindo o antigo Código Florestal, instituído pela Lei n. ${ }^{\circ} 4.771 / 65$, não evolui no que diz respeito a noção de participação observada no Código Florestal de 1965 e nem tampouco nas alterações realizadas em 1989.

As ideias associadas ao conceito de participação na Lei n. 12.651/12 ainda estão fortemente vinculadas exclusivamente à noção de compartilhamento na responsabilidade de proteção da natureza. A afirmação expressa no inciso IV, do art. $1^{\circ}$, vislumbra a participação da sociedade na formulação de políticas públicas para a proteção da natureza: "responsabilidade comum da União, Estados, Distrito Federal e Municípios, em colaboração com a sociedade civil, na criação de políticas para a preservação e restauração da vegetação nativa e de suas funções ecológicas e sociais nas áreas urbanas e rurais" (BRASIL, 2012, art. 1º, inciso IV). Apesar disso, no decorrer do texto não é possível observar nenhuma menção a práticas análogas às descritas neste inciso. 
A partilha da responsabilidade de proteger a natureza em consonância com o Estado é observada na definição de Reserva Legal, conceito que persiste na Lei n. 12.651/12, com algumas alterações da formulação realizada anteriormente, na Lei n. 7.803/89. No novo Código Florestal de 2012 a Reserva Legal passa a ser conceituada como:

Área localizada no interior de uma propriedade ou posse rural, delimitada nos termos do art. 12, com a função de assegurar o uso econômico de modo sustentável dos recursos naturais do imóvel rural, auxiliar a conservação e a reabilitação dos processos ecológicos e promover a conservação da biodiversidade, bem como o abrigo e a proteção de fauna silvestre e da flora nativa (BRASIL, 2012, art. $3^{\circ}$, inciso III).

Apesar das alterações na definição, a questão da participação é cogitada nos mesmos termos observados na Lei n. 7.803/89, onde a sociedade, no interior de suas propriedades auxilia o governo a preservar a natureza ali encerrada. É importante ressaltar que se entende no presente artigo a importância das Reservas Legais para a proteção da natureza. Os questionamentos aqui inseridos não são alusivos à relevância dessas áreas. O que se questiona é que são poucos os pontos nos quais se observa a inclusão da sociedade na Lei n. 12.651/12, e esta inserção é realizada apenas na premissa do dever. A alegação constitucional, do direito a participação ativa nas decisões e debates das questões ambientais é extremamente limitada no Código Florestal de 2012.

Existe, assim como observado na Lei n. 4.771/65, certa preocupação com as características locais e as peculiaridades das populações rurais, como é possível observar no art. 38, que regulamenta o uso de fogo nas práticas agropastoris ou florestais, e permite que esse seja utilizado em certas situações caso aprovado pelo órgão ambiental competente.

Ao contrário da Lei n. 9.985/00, o documento não prevê o estabelecimento de instituições participativas. Mesmo nas hipóteses de utilidade pública e interesse social, não é cogitada a participação na decisão, no debate e na execução das ações.

Por fim, foi constatado um possível retrocesso, quando avaliado comparativamente ao princípio da informação presente na Lei n. 4.771/65, na qual há abordagem sobre a inclusão de textos sobre educação florestal em livros didáticos e o acesso à informação sobre florestas através das mídias, assim como a obrigatoriedade da manutenção de escolas cujo objetivo é o ensino florestal. Todos esses valores associados ao princípio da informação são excluídos definitivamente na Lei n. 12.651/12, sem que 
houvesse alguma alteração para introduzir essa discussão de forma mais atualizada neste último documento.

Apesar da ampliação da discussão sobre a temática da participação na legislação brasileira, o Código Florestal de 2012 não segue essa tendência. No intuito de tentar explicar a razão da não adequação dessa Lei nesse quesito, cabe aqui ressaltar as circunstâncias de criação da Lei n. 12.651/12, que surge imersa em conflitos entre ruralistas e ambientalistas/ pesquisadores (ALMEIDA; CASTELO; RIVERO, 2013).

A Lei n. 12.651/12 surgiu repleta de intencionalidades e interesses de um grupo político específico - a Frente Parlamentar da Agropecuária (FPA), também conhecida como bancada ruralista - visando obter benefícios e minimizar problemas relativos ao agronegócio (LAMIM-GUEDES, 2013). Representantes dessa bancada alegavam que o Código Florestal restringia o crescimento do agronegócio e da produção de alimentos. Um deputado chegou a declarar que a instituição da Reserva Legal seria um absurdo, pois constitui em confisco da propriedade, já que subtrai $20 \%$ de toda propriedade rural (SAUER; FRANÇA, 2016).

Isso posto, pode-se observar que a Lei n. 12.651/12 foi sancionada primordialmente para sanar os interesses de uma classe política, o que tornou secundária a apreciação de outras temáticas para a composição dessa Lei, como ocorreu com as questões sobre participação. Embora muitos ambientalistas, pesquisadores e movimentos sociais tenham denunciado em inúmeras instâncias e publicações os retrocessos do ponto de vista ambiental que as alterações realizadas no Código Florestal poderiam alcançar.

Nesse sentido, foram ajuizadas quatro Ações Diretas de Inconstitucionalidade (ADIs), três de autoria da Procuradoria Geral da República (ADIs 4901, 4902, 4903) e uma (ADI 4937) ajuizada pelo Partido Socialismo e Liberdade (PSOL), além de uma Ação Declaratória de Constitucionalidade (ADC) pelo Partido Progressista (PP). As ações de inconstitucionalidade tinham como principal fundamento o princípio da proibição do retrocesso ambiental. No entanto, em julgamento realizado em fevereiro de 2018, o Supremo Tribunal Federal (STF) declarou a constitucionalidade da Lei n. 12.651/12, declarando a inconstitucionalidade apenas em algumas expressões contidas em seus artigos; como nos exemplos das expressões "instalações necessárias à realização de competições esportivas estaduais, nacionais ou internacionais" e "gestão de resíduos" sendo entendidas como situações de utilidade pública (BRASIL, 2012, 
art. $3^{\circ}$, inciso VIII), e, portanto, passíveis de acarretar intervenção ou a supressão de Áreas de Preservação Permanente (BRASIL, 2012, art. $8^{\circ}$ ).

Não obstante os avanços legais com relação à promoção da participação na legislação, como ocorrem no SNUC e no PNAP, muitos progressos permanecem na teoria. Na prática existem algumas conjunturas políticas, econômicas e sociais que impedem a inserção de práticas participativas de maneira plena, como é possível observar nas discussões relacionadas à Lei n. 12.651/12 e na atual publicação do Decreto n. 9.759/19.

\section{CONSIDERAÇÕES FINAIS}

Ao tecer esse pequeno histórico sobre a relação das políticas participativas na legislação brasileira referente às áreas protegidas, é possível observar que existe uma orientação para se efetivar a corresponsabilidade a respeito da proteção de áreas protegidas entre Poder Público e sociedade desde a publicação do Código Florestal de 1965 (Lei n. 4.771/65). No entanto, a Lei n. 4.771/65, não estabelece a participação da sociedade em instâncias decisórias; esta Lei possui como foco a participação realizada nas formas de auxílio ao Estado, como é possível observar no art. 16 da referida Lei, relativo às florestas de domínio privado, segundo o qual o proprietário é o responsável pela proteção dos recursos florestais de sua propriedade; a participação é neste contexto partilhada, mas também compulsória.

Com o passar dos anos as discussões tornam-se cada vez mais sólidas e passam a ser embasadas na perspectiva de que a participação é benéfica tanto para a sociedade quanto para as áreas protegidas. Essa tendência de ampliação do discurso em prol da participação da sociedade civil em instâncias decisivas surge a partir da década de 1980 com o advento da Constituição de 1988. Desse modo, a legislação relativa às áreas protegidas que desponta no início do XXI tem como característica o fortalecimento do entendimento do conceito de participação.

No entanto, apesar dos avanços observados na Lei n. 9.985/00 e no Decreto n. 5.758/06, o Código Florestal de 2012, devido às conjunturas políticas específicas, mantem-se o entendimento do conceito de participação apenas como o dever da sociedade em colaborar com o Estado na proteção do meio ambiente.

Por fim, o estudo das leis relativas às áreas protegidas no Brasil possibilitou a observação de que o entendimento de participação 
observado nesses documentos faz parte de um processo histórico pontuado por disputas em torno da participação política no país. Trata-se de um tema que se transforma ao sabor dos embates entre posições e interesses divergentes no contexto nacional. Em meio às disputas de interesses, a legislação introduziu a participação em áreas protegidas, nos anos 1960, sob uma ótica mais restrita e autoritária, mas nas décadas seguintes evoluiu a ideia de participação, ampliando-a no sentido da tomada de decisões com participação da sociedade, de forma gradativa, até os anos 2000.

Desse modo, pode-se observar que essas mudanças não foram espontâneas, de maneira oposta, foram resultados de indagações, investigações, avaliações de experiências anteriores, de participação e lutas políticas, que permanecem até os dias de hoje. Portanto, o conceito de participação em áreas protegidas não está encerrado e continua sofrendo transformações e reformulações.

\section{REFERÊNCIAS}

ALMEIDA, O. T.; CASTELO, T. B.; RIVERO, S. L. M. Avaliação dos stakeholders em relação às mudanças na legislação ambiental e reforma do Código Florestal Brasileiro. Desenvolvimento e Meio Ambiente, Curitiba, v. 27, p. 163-177, 2013.

AVRITZER, L. A qualidade da democracia e a questão da efetividade da participação: mapeando o debate. In: PIRES, R. R. C. (Org.). Efetividade das instituições participativas no Brasil: estratégias de avaliação. Brasília: Ipea, 2011. p. 13-25. Disponível em: <http://www.ipea.gov.br/ portal/images/stories/PDFs/livros/livro_dialogosdesenvol07.pdf $>$. Acesso em: 27 jun. 219.

AVRITZER, L. Impasses da democracia no Brasil. 3. ed. Rio de Janeiro: Civilização Brasileira, 2016.

BORDENAVE, J. D. O que é participação. 3. ed. São Paulo: Brasiliense, 1985.

BRASIL. Lei n. 4.771, de 15 de setembro de 1965. Institui o Novo Código Florestal. Diário Oficial da União, Brasília, DF, 16 set. 1965. Disponível em: <http://www.planalto.gov.br/ccivil_03/leis/L4771.htm>. Acesso em: 27 jun. 219. 
BRASIL. Lei n. 7.347, de 24 de julho de 1985. Disciplina a ação civil pública de responsabilidade por danos causados ao meio-ambiente, ao consumidor, a bens e direitos de valor artístico, estético, histórico e dá outras providências. Diário Oficial da União, Brasília, DF, 25 jul. 1985. Disponível em: <http://www.planalto.gov.br/ccivil_03/leis/17347orig. htm>. Acesso em: 27 jun. 219.

BRASIL. Conselho Nacional do Meio Ambiente. Resolução n. 001, de 23 de janeiro de 1986. Diário Oficial da União, Brasília, DF, 17 fev. 1986. Disponível em: <https:/www.ibama.gov.br/sophia/cnia/legislacao/MMA/ RE0001-230186.PDF>. Acesso em: 26 jun. 2019.

BRASIL. Constituição da República Federativa do Brasil de 1988. Diário Oficial da União, Brasília, DF, 5 out. 1988. Disponível em: <http://www. planalto.gov.br/ccivil_03/constituicao/constituicao.htm>. Acesso em: 27 jun. 219.

BRASIL. Lei n. 7.803, de 18 de julho de 1989. Altera a redação da Lei n. 4.771 , de 15 de setembro de 1965, e revoga as Leis n. 6.535, de 15 de junho de 1978, e n. 7.511, de 7 de julho de 1986. Diário Oficial da União, Brasília, DF, 20 jul. 1989. Disponível em: <http://www.planalto.gov.br/ ccivil_03/leis/L7803.htm>. Acesso em: 26 jun. 2019.

BRASIL. Lei n. 9.784, de 29 de janeiro de 1999. Regula o processo administrativo no âmbito da Administração Pública Federal. Diário Oficial da União, Brasília, DF, 1 fev. 1999. Disponível em: <http://www.planalto. gov.br/ccivil_03/leis/19784.htm>. Acesso em 23 jun. 2019.

BRASIL. Lei n. 9.985, de 18 de julho de 2000. Regulamenta o art. 225, § $1^{\circ}$, incisos I, II, III e VII da Constituição Federal, institui o Sistema Nacional de Unidades de Conservação da Natureza e dá outras providências. Diário Oficial da União, Brasília, DF, 19 jul. 2000. Disponível em: $<$ http://www. planalto.gov.br/ccivil_03/leis/19985.htm>. Acesso em: 23 jul. 2019.

BRASIL. Lei n. 10.650, de 16 de abril de 2003. Dispõe sobre o acesso público aos dados e informações existentes nos órgãos e entidades integrantes do Sisnama. Diário Oficial da União, Brasília, DF, 17 abr. 2003. Disponível em: <http://www.planalto.gov.br/ccivil_03/LEIS/2003/ L10.650.htm>. Acesso em: 26 jun. 2019. 
BRASIL. Decreto n. 5.758, de 13 de abril de 2006. Institui o Plano Estratégico Nacional de Áreas Protegidas - PNAP, seus princípios, diretrizes, objetivos e estratégias, e dá outras providencias. Diário Oficial da União, Brasília, DF, 17 abr. 2006. Disponível em: <http://www.planalto. gov.br/ccivil_03/_Ato2004-2006/2006/Decreto/D5758.htm>. Acesso em: 27 jun. 2019.

BRASIL. Lei n. 12.651, de 25 de maio de 2012. Dispõe sobre a proteção da vegetação nativa; altera as Leis n. 6.938, de 31 de agosto de 1981, 9.393, de 19 de dezembro de 1996, e 11.428, de 22 de dezembro de 2006; revoga as Leis n 4.771, de 15 de setembro de 1965, e 7.754, de 14 de abril de 1989, e a Medida Provisória n. 2.166-67, de 24 de agosto de 2001; e dá outras providências. Diário Oficial da União, Brasília, DF, 28 maio 2012. Disponível em: <http://www.planalto.gov.br/ccivil_03/_Ato20112014/2012/Lei/L12651.htm>. Acesso em: 24 jun. 2019.

BRASIL. Decreto n. 8.243, de 23 de maio de 2014. Institui a Política Nacional de Participação - PNPS e o Sistema Nacional de Participação Social - SNPS, e dá outras providências. Diário Oficial da União, Brasília, DF, 25 maio 2014. Disponível em: <http://www.planalto.gov.br/ccivil_03/_ Ato2011-2014/2014/Decreto/D8243.htm>. Acesso em: 27 jun. 2019.

BRASIL. Decreto n. 9.759, de 11 de abril de 2019. Extingue e estabelece diretrizes, regras e limitações para colegiados da administração pública federal. Diário Oficial da União, Brasília, DF, 11 abr. 2019. Disponível em: <http://www.planalto.gov.br/ccivil_03/_ato2019-2022/2019/decreto/ D9759.htm>. Acesso em: 27 jun. 2019.

CARVALHO, J. M. Cidadania no Brasil: o longo caminho. 12. ed. Rio de Janeiro: Civilização Brasileira, 2009.

COMPARATO, F. K. Para viver a democracia. São Paulo: Brasiliense, 1989.

COUTINHO, C. N. De Rousseau a Gramsci: ensaios de teoria política. São Paulo: Boitempo, 2011.

DAGNINO, E. Sociedade civil e espaços púbicos no Brasil. In: DAGNINO, E. (Org.). Sociedade civil e espaços públicos no Brasil. São Paulo: Paz e Terra/UNICAMP, 2002. p. 9-15. 
DAGNINO, E. Sociedade civil, participação e cidadania: de que estamos falando? In: MATO, D. (Org.). Politicas de cidadania y sociedade civil en tiempos de globalizacion. Caracas: Universidad Central de Venezuela, 2004. p. 95-110.

DAGNINO, E.; OLVERA, A.. J.; PANFICHI, A. Para uma outra leitura da disputa pela construção democrática na América Latina. In: DAGNINO, E.; OLVERA, A. J.; PANFICHI, A. (Orgs.). A disputa pela construção democrática na América Latina. São Paulo: Paz e Terra; Campinas: Unicamp, 2006. p. 13-91.

DEMO, P. Participação é conquista. São Paulo: Cortez, 1988.

GOHN, M. G. Conselhos gestores e participação sociopolítica. 4. ed. São Paulo: Cortez, 2011.

GODOY, A. S. Pesquisa qualitativa: tipos fundamentais. Revista de Administração de Empresas, São Paulo, v. 35, n. 3, p. 20-29, 1995.

IRVING, M. A.; GIULIANI, G. M.; LOUREIRO, C. F. B. Natureza e sociedade: desmistificando mitos para a gestão de áreas protegidas. In: IRVING, M. A.; GIULIANI, G. M.; LOUREIRO, C. F. B. (Orgs.). Parques estaduais do Rio de Janeiro: construindo novas práticas para a gestão. São Carlos: Rima, 2008. p. 1-19.

IRVING, M. A. Áreas protegidas e inclusão social: uma equação possível em políticas públicas de proteção da natureza no Brasil? Sinais Sociais, Rio de Janeiro, v. 4, n. 12, p. 122-147, 2010.

JACOBI, P. Poder local, políticas sociais e sustentabilidade. Saúde e Sociedade, São Paulo, v. 8, n.1, p. 31-48, 1999.

LAMIM-GUEDES, V. O Código Florestal brasileiro: divergências entre a política e evidências científicas. Holos Environment, Rio Claro, v. 13, n. 2 , p. 122-129, 2013.

LAVALLE, A. G. Participação: valor, utilidades, efeitos e causa. In: PIRES, R. R. C. (Org.). Efetividade das instituições participativas no Brasil: estratégias de avaliação. Brasília: Ipea, 2011. p. 33-42.

LOUREIRO, C. F. B. Educação ambiental transformadora. In: BRASIL. 
Ministério do Meio Ambiente. Identidades da educação ambiental brasileira. Brasília: Edições MMA, 2004. p. 65-84.

LOUREIRO, C. F. B. Sustentabilidade e educação: um olhar da ecologia política. São Paulo: Cortez, 2012.

LOUREIRO, C. F. B.; AZAZIEL, M.; FRANCA, N. Educação ambiental e gestão participativa em unidades de conservação. Rio de Janeiro: Ibase, 2003.

MACHADO, P. A. L. Direito Ambiental brasileiro. 21. ed. São Paulo: Malheiros, 2013.

MALTEZ, R. T. Manual de Direito Ambiental. São Paulo: Se-lo, 2016.

MILARÉ, É. Princípios fundamentais do direito do ambiente. Revista Justitia, São Paulo, v. 181/184, 1998. Disponível em: <http://egov.ufsc.br/ portal/sites/default/files/anexos/31982-37487-1-PB.pdf $>$. Acesso em: 20 mar. 2017.

MIGUEL, L. F. Igualdade e democracia no pensamento político. In: MIGUEL, L. F. (Org.). Desigualdades e democracia: o debate da teoria política. São Paulo: Unesp, 2016. p. 7-23.

MINAYO, M. C. S. Ciência, técnica e arte: o desafio da pesquisa social. In: MINAYO, M. C. S. (Org.). Pesquisa social: teoria, método e criatividade. 21. ed. Petrópolis: Vozes, 2002.

PATEMAN, C. Participação e teoria democrática. Rio de Janeiro: Paz e Terra, 1992.

REED, M. S. Stakeholder participation for environmental management: a literature review. Biological Conservation, v. 4, p. 2417-2431, 2008.

SAUER, S.; FRANÇA, F. C. Código Florestal, função socioambiental da terra e soberania alimentar. Caderno $C R H$, Salvador, v. 25 , n. 65, p. $285-$ $-307,2016$.

Artigo recebido em: 10/04/2019. Artigo aceito em: 29/07/2019. 


\section{Como citar este artigo (ABNT):}

SOUZA, R.; LEAL, F. G.; MACIEL, F. M. Participação da sociedade em áreas protegidas: perspectivas da legislação ambiental brasileira. Veredas do Direito, Belo Horizonte, v. 16, n. 35, p. 403-426, maio/ago. 2019. Disponível em: <http://www.domhelder.edu.br/revista/index.php/veredas/ article/view/1515>. Acesso em: dia mês. ano. 